tube ; (3) the influence of the head of liquid on the curvature of these lines. As all of these admit of exact mathematical treatment, it should be possible, by running a gram-molecule of the liquid, to calculate $\mathrm{W}_{m}$. This would be entirely independent of the velocity of flow and would represent the relative molecular gyro-viscosity. Whereas the ordinary figures for absolute viscosity appear to bear no general relationship to the other physical constants of the liquid, it is possible that these values might be more productive of results. A thorough investigation of these lines of flow is therefore the first necessary step towards the solution of this most interesting problem.

37 Powell St., Derby,

November I.

\section{New Weights and Measures for India.}

I HAVE read with interest the article in NATURE of September 2, p. 325, on the weights and measures of India by Mr. Silberrad, president Indian Weights and Measures Committee. Mr. Silberrad reports conditions much the same as I found them in India in I9Io. One of the pleasures in reading NATURE is that the desirability of producing commodities and methods of service is taken for granted. Now in attacking this problem it is assumed that a simple, useful system of weights and measures is desired for India. While in India I was asked to rewrite the article on weights and measures for the "Times Year-book," and in looking up data in this connexion, I came across the permissive Metric Act of $187 \mathrm{r}$. This Act represents one of the attempts of the leaders of India to secure the advantages of the general use of the metric system. By it the Viceroy of India is empowered to make what preliminary arrangements might be necessary, and proclaim the date after which metric weights and measures shall come into general use.

Let us consider the various necessary units of measurement in their logical order.

I. Mr. Silberrad rightly mentions " the Peshawari yard of 38 in. to $38 \frac{3}{4}$ in.," and also the yard of approximately 40 inches. Also the Ilahi gaz, which is frequently in the neighbourhood of, if not exactly, 39.37 inches or one metre. These are only a few examples of units of length in a country of approximate lengths that could be best standardised on the international metre.

2. Practically the same thing is true of measures of area. Nearly all of the British engineers that I have met have favoured the metric system, and few have any desire to continue the use of such a difficult unit as the acre. The square metre and the hectare of 10,000 square metres are good and sufficient, and will, we believe, be used eventually in all civilised countries. Several of the Indian units fortunately approximate to the hectare.

3. The suggestion that "the standardisation of suitable measures of capacity at the nearest suitable multiple of the bulk of $I_{\frac{1}{4}}$ seers of water, this being approximately equivalent to the bulk of a seer of wheat," is not so unfortunate as it may seem. This probably will soon become the litre.

4. My findings also correspond with those of $\mathrm{Mr}$. Silberrad in reference to the tola of 180 grains, about I 2 grams. This brings the seer to approximately I kilogram. When it is understood that the seer has been adopted for practically all railroad transactions in India by the British Government, one realises that India is using the metric system in what amounts to 60 per cent. of all accurate transactions according to weight.
It was my pleasure to spend part of the past summer in England, and confer in regard to the metric campaign with members of the Decimal Association and others who are actively interested in the metric movement. I found a general desire to secure the advantages of decimal currency and metric weights and measures. It was forcibly brought home to me that the chief men of England who have the vision of service and big foreign trade will not only encourage the Colonies to make progress in the metric movement, but will also see to it that the British Government leads the way in this muchneeded reform. Readers of NATURE will be interested to see the following statement by Prof. J. C. McLennan of Toronto University: "In the early part of 1906, at the request of the Hon. L. P. Brodeur, Minister of Inland Revenue of the Dominion Government of Canada, I agreed to deliver a number of lectures on the use of metric weights and measures.

"Through the co-operation of the Department mentioned, a schedule of the lectures was arranged, and it was made known in various centres throughout Canada that my services in connexion with the metric campaign would be available on certain dates for the various local societies interested in this subject.

"In carrying out this rather strenuous schedule, lectures were given in Montreal, Ottawa, Toronto, Winnipeg, Regina, Vancouver, and in over 30 other Canadian cities. In some places the idea of the simple metric system corresponding to decimal currency was then new to many people. Our meetings were well attended, in some cases as many as 600 people being present. At the close of each address, all present were invited to take part in the discussion of the subject. The pros and cons were propounded with the utmost frankness, and in some cases with considerable vigour. Never during this lecture tour or at any other time have I heard, in so far as I can judge, a really valid argument against the general use of metric weights and measures. On the other hand, the many valid reasons for their use increase as time passes.

"It is highly desirable that this preliminary educational work, conducted entirely at the expense of our Government, should be effectively followed up. It is chiefly for the purpose of encouraging others to do their part in securing for Canada the advantages of the use of the metric system that on April 28, I922, I accepted the Chairmanship of the Toronto Section of the American Metric Association. At that time Mr. W. P. Dobson of the Hydro-Electric Power Commission was elected Secretary, and Mr. L. Burpee, of the Canadian General Electric Company, Ltd., was elected Treasurer. Our Section is composed of volunteer workers, who desire to see the metric campaign progress as it should. We believe that everybody can do something to help. We hope that a great many people will let Mr. Dobson know that they will help the metric movement in their own industry or line of work."

It may seem a far cry from Canada to India, but there is a direct connexion when one realises that the various peoples of the world can understand and serve each other best when they use the same convenient weights and measures. The members of the American Association are determined to secure these advantages in the United States and Canada, and we ask for the hearty co-operation of all progressive men and women throughout the world.

\section{HowaRD RichaRds}

(Secretary).

American Metric Association, I 56 Fifth Avenue, New York. 